\title{
Prostate-specific antigen screening for prostate cancer: benefits for patients with highly aggressive prostate cancer
}

\author{
Hui-Jie Jia ${ }^{1,2}$, Yang Li $^{1}$, Jin-Guo Wang ${ }^{1}$, Ling Zhang ${ }^{1}$, Hai-Tao Zhang ${ }^{3}$, Xue-Jian Zhao ${ }^{1}$ and Masaaki Kuwahara ${ }^{4}$ \\ Asian Journal of Andrology (2013) 15, 218-220; doi:10.1038/aja.2012.130; published online 21 January 2013
}

$\mathrm{T}$ he US Preventive Services Task Force (USPSTF) analyzed the benefits and harms of prostate specific antigen (PSA)based screening for prostate cancer (PCa). The Grade ' $D$ ' recommendation of the USPSTF was based mainly on the Prostate, Lung, Colorectal, and Ovarian (PLCO) study in the United States. That result showed only a small reduction in PCa mortality. However, the data from the International Agency for Research on Cancer (IARC) illustrated the PCa mortality rate (MR) decreased marked. To avoid the over-diagnosis and over-treatment, the American Cancer Society has changed its strategy and updated its guidance. The USPSTF neglected the aggressive PCa accounted for more then $30 \%$ of all PCa. Highly aggressive PCa can be diagnosed by PSA screening combined with Gleason grade. We hope that the USPSTF changes the ' $D$ ' recommendation for PSA screening.

The US Preventive Services Task Force (USPSTF) analyzed the benefits and harms of prostate-specific antigen (PSA)-based screening for prostate cancer $(\mathrm{PCa})^{1-3}$ and gave it ' $\mathrm{D}$ ' recommendation that meant they recommended against PSA-based screening

${ }^{1}$ Department of Pathophysiology, Prostate Diseases Prevention and Treatment Research Centre, Norman Bethune College of Medicine, Jilin University, Changchun 130021, China; ${ }^{2}$ Laboratory of Transplantation and Immunology, Xuzhou Medical College, Xuzhou 221000, China; ${ }^{3}$ Department of Pathology and Laboratory Medicine, and Tulane Cancer Center, Tulane University School of Medicine, New Orleans, LA 70112, USA and ${ }^{4}$ Sendai Reno-Urological Clinic, 3-1-32 Minami-yoshinari, Sendai 9893204, Japan

Correspondence: Dr XJ Zhao (zhaoxuejian2007@ yahoo.com.cn) and Dr M Kuwahara (adataranzk171@ yahoo.co.jp)

Received: 7 August 2012; Revised: 7 October 2012; Accepted: 30 October 2012; Publiahed online: 21 January 2013 for PCa in all age groups for updated data in $2012 .^{3}$ In that paper, the USPSTF emphasized the good prognosis of most patients with PCa; however, they neglected the aggressive PCa (Gleason grade 4/5) that account for more than $30 \%$ of all $\mathrm{PCa}$ patients. ${ }^{4}$ Additionally, the task force stated that PSA screening did not reduce the mortality rate (MR) of $\mathrm{PCa},{ }^{5}$ whereas the data from the International Agency for Research on Cancer (IARC) indicated that both the incidence rate (IR) and MR were significantly reduced. ${ }^{6,7}$ Although we mostly agree with the task force's analysis, we have some conflicting opinions on this issue.

\section{THE INCIDENCE AND MORTALITY OF PCA AFTER PSA SCREENING}

Routine PSA screening significantly reduced the incidence and the mortality of PCa in North America

Among the numerous studies of PCa IR and PCa MR after the PSA-based screening for $\mathrm{PCa}$, we noticed the data from the IARC and GLOBOCAN ${ }^{6,7}$ on PCa and analyzed them carefully. The PCa IR was $85.7 / 10^{5}$ person year (PY) in North America in $2008,{ }^{6}$ which was significantly lower than that in $2002^{7}\left(119.9 / 10^{5} \mathrm{PY}\right)$, and the PCa MR decreased dramatically from 2002 to $2008\left(15.8 / 10^{5}\right.$ PY versus $\left.9.9 / 10^{5} \mathrm{PY}\right)$. The authors attributed this remarkable difference to the widespread PSA screening in North America. Kamangar et al. ${ }^{8}$ performed retrospective studies regarding the various cancer incidence, mortality and prevalence across five continents. These studies were based on the databases from GLOBOCAN in 2002. A comparison revealed that PCa IR was $119.9 / 10^{5} \mathrm{PY}$ in North America, which was nearly 25.5 times higher than that of
Asia $\left(4.7 / 10^{5} \mathrm{PY}\right)$. However, the MR/IR ratio was only 0.13 in North America, but that value reached up to 0.57 in Asia. The authors considered that the large difference between the two continents could not stem from variations in diet and race, but it instead occurred because the PSA-based screening for PCa was only performed on one of the continents. Our group conducted the first PSA-based screening in Changchun, China from 1999 to 2002 for 12027 men over 50 years old. The results showed that the overall $\mathrm{PCa}$ detection rate was $1.7 \%$ and that the cases with Stages ' $C$ ' and ' $D$ ' accounted for $42.1 \%$ of all cancer cases. $^{9,10}$

Routine PSA screening significantly reduced the mortality of PCa in Asian Americans

McCracken et al. ${ }^{11}$ analyzed the incidence of major cancers, including prostate, lung, liver and colorectal, in different ethnic groups of Asian Americans living in California in 2007. The data were obtained from the Los Angeles Cancer Surveillance Program and the California Cancer Registry between 2000 and 2002. ${ }^{12}$ The average PCa IR of Asian Americans was $82.7 / 10^{5} \mathrm{PY}$, which was 14.6 times higher than that of Asian individuals (4.7/10 5 PY). However, the average $\mathrm{MR} / \mathrm{IR}$ ratio was only 0.135 in Asian Americans, whereas it reached up to 0.57 in Asians. According to the information above, we believe that the seemingly low incidence of PCa in Asia is the result of a lack of population-based PSA screening. In that situation, the disease is often diagnosed at a later stage with poorer prognosis. While the higher incidence of PCa in Asian Americans resulted from the widely used PSA screening in the 
United States, most of the diseases could be diagnosed at the early stage, where the MR/IR ratio should be lower despite the high IR.

The ' $D$ ' recommendation of the USPSTF on PCa screening was mainly based on the prostate, lung, colorectal and ovarian (PLCO) study

The PLCO cancer screening trial study was conducted from 1993 to 2001 in the United States. ${ }^{5}$ The researchers used PSA and digital rectal examinations as PCa screening methods and showed only a small reduction in PCa mortality after 7-10 years of follow-up. This PLCO study was initiated in 1993, and the data were collected for 6years after the introduction of PSA screening in the United States. ${ }^{5}$ According to a number of articles, ${ }^{12,13} 95 \%$ of urologists in the United States considered that PSA screening was feasible, and most men aged 50 years or older joined the screening freely on their own initiative. Therefore, the insignificant difference in PCa mortality rate between the PSA-screened and controlgroups was likely attributable to data contamination. For instance, people in the control group had already had a PSA examination before they entered the nearest study. This may bias the validity of the study results and conclusions.

Schroder et al. ${ }^{14}$ recently reported the result of PCa mortality after 11 years of follow-up for the European Randomized Study of Screening for Prostate Cancer (ERSPC) group. The authors noted that PSA screening significantly reduced the mortality from $\mathrm{PCa}$, though it did not affect all causes of mortality. They showed that the relative reduction in the risk of death from $\mathrm{PCa}$ in the screening group was $21 \%$. Relatively large PSA-test contamination exists in the previous two reports, but the rate of contamination in the PLCO ( $44 \%$ of the men in each study group) was much greater than that of ERSPC $(20 \%)$. The result of the latter study is thus more reliable than the former.

\section{HIGHLY AGGRESSIVE PCA CAN BE DIAGNOSED BY PSA SCREENING COMBINED WITH GLEASON GRADE}

PCa can be diagnosed via PSA-based screening at the early stage without decreasing the detection rate of aggressive cancer

Stamey et al. ${ }^{4}$ reviewed preoperative serum PSA and pathologic data of 1317 patients who underwent prostatectomy between 1983 and 2003. They found that during the first 5-year period, the mean preoperative serum PSA level was $24.74 \pm 38.08 \mathrm{ng} \mathrm{ml}^{-1}$, the positive diagnostic rate of digital rectal examination was up to $90.79 \%$ and $30.89 \%$ of the patients were Gleason grade 4/5. By the fourth 5-year period, the mean PSA level had dropped to $8.14 \pm 9.70 \mathrm{ng} \mathrm{ml}^{-1}$, and the positive diagnostic rate of digital rectal examination also decreased to $16.76 \%$, but the patients with Gleason grade $4 / 5$ remained in almost the same range $(35.03 \%)$. We could deduce two important conclusions from this article: (i) the diagnoses of PCa patients were in their late stage before adoption of PSA screening and (ii) the detection rate for the aggressive PCa with Gleason grade 4/5 remained almost the same after introducing screening. Therefore, the patients with aggressive PCa would obtain opportunities for effective treatment via PSA screening, and a prolonged high-quality life span could be expected. ${ }^{15}$ Our results ${ }^{16}$ also indicated that $34 \%$ of all cases had a Gleason grade of $4 / 5$, as detected by the PSA screening in Changchun, China. Additionally, the late-stage aggressive PCa patients did not visit urologists until the development of a urinary disorder, such as pain during urination, bloody urine or difficult urination. These symptoms generally occurred at the later stages of cancer. In other words, only PSA screening could diagnose and save the life of patients with highly aggressive PCa, though not all.

PSA screening facilitates earlier prediction of micrometastases

The survival rate of the metastatic PCa is poor, and the micrometastases of aggressive PCa (Gleason grade 4/5) often occur at the early stage of PCa. Several articles indicate that the 5-year survival rate of localised $\mathrm{PCa}$ was more than $99 \%,{ }^{17,18}$; however, that of the widely metastatic PCa was only $31 \% .{ }^{18}$ Our group analyzed the micrometastasis in $\mathrm{PCa}$ patients using PSA mRNA expression in peripheral blood mononuclear cells. The casecontrol study showed that the rate of micrometastasis reached $85.7 \%$ in patients with a $\mathrm{PSA}<20 \mathrm{ng} \mathrm{ml}^{-1}$ and Gleason scores $\geqslant 8$, but in patients with Gleason scores $\leqslant 6$, micrometastasis scarcely occurred. However, if the PSA level $>40 \mathrm{ng} \mathrm{ml}^{-1}$, the rate of micrometastasis reached $82.61 \%$, even if the Gleason scores were $\leqslant 6$. $^{16}$

\section{OVERDIAGNOSIS, OVERTREATMENT AND COMPLICATIONS CAUSED VIA ROUTINE PSA SCREENING}

Efforts should be made to decrease overdiagnosis in PSA screening

The diagnostic criteria of aggressive PCa is Gleason grade $4 / 5$ (Gleason scores $\geqslant 8$ ), and this type of PCa accounts for $30 \%-35 \%$ of all
PCa instances diagnosed via PSA screening. Micrometastasis could occur in the early stage, which could be the main cause of death later due to multiple metastases. ${ }^{19}$ In this regard, among the patients with earlier $\mathrm{PCa}$ and Gleason scores $\leqslant 6$, overdiagnosis and overtreatment could be unavoidable to some extent. However, no one could confirm the malignancy of PCa without pathologic diagnosis. To avoid the overdiagnosis and overtreatment, the American Cancer Society has changed its strategy and updated its guidance based specifically on PSA levels, ${ }^{20}$ which seems to be more appropriate under the current circumstances.

Complications of PCa biopsy and treatment may be avoidable using a skilled and hightech operation

The Rotterdam study reported the significant complications after prostate biopsy. ${ }^{21,22}$ The abnormally high complications reported might result from several factors, including the inexperience of doctors, a lack of infection prevention, and insufficient rectal cleaning and disinfection. With regard to the complications such as erectile dysfunction and urinary incontinence, improving techniques further will solve these problems. For example, if a pelvic nerve has not been invaded by cancer cells, the minimally invasive technique is applicable to preserve the nerve. Additionally, recently developed laparoscopic and robot-assisted surgical techniques can help prevent complications. $^{23,24}$ Furthermore, preventable urinary incontinence is now more expected than it was previously, and it usually disappears within 2-3 months after radical prostatectomy. ${ }^{25}$

The complications of PCa biopsy and treatment depicted in the updated data from the USPSTF in 2012 could not be overlooked, ${ }^{22}$ but complications can be avoided through improving medical technology and expertise. The past 25 years of PSA screening in the United States won the people's trust, and patients began participating on their own initiative. Additionally, the surgical complications for PCa biopsies have been decreasing in the United States. ${ }^{26}$

\section{SUMMARY}

The PSA screening for 25 years in America is the biggest cohort study in a field of public health. ${ }^{27}$ We should realize not only the significance of the early diagnosis and treatment of PCa, but also the dramatic decrease in $\mathrm{PCa}$ MR from 2002 to 2008. The data from the IARC were especially noteworthy. Moreover, the patients with highly aggressive $\mathrm{PCa}$, who account for more than $30 \%$ of all 
PCa patients, could only be diagnosed earlier by PSA screening. The patients would thus gain the opportunity for earlier treatment and would have a prolonged, higher quality life-span. However, the complications of interventional treatments, including biopsy, radical prostatectomy and/or radiation therapy, will become more avoidable in the near future. According to the supporting evidence for the decrease in PCa mortality in PSA screening, we strongly hope that the USPSTF changes the ' $D$ ' recommendation for PSA screening.

1 Harris R, Lohr KN. Screening for prostate cancer: an update of the evidence for the U.S. Preventive Services Task Force. Ann Intern Med 2002; 137: 917-29.

2 US Preventive Services Task Force. Screening for prostate cancer: U.S. Preventive Services Task Force recommendation statement. Ann Intern Med 2008; 149: 185-91.

3 Moyer VA. Screening for prostate cancer: U.S. Preventive Services Task Force recommendation statement. Ann Intern Med 2012; 157: 120-34.

4 Stamey TA, Caldwell M, McNeal JE, Nolley R, Hemenez $\mathrm{M}$ et al. The prostate specific antigen era in the United States is over for prostate cancer: what happened in the last 20 years? J Urol 2004; 172: 1297-301.

5 Andriole GL, Crawford ED, Grubb RL, 3rd, Buys SS, Chia $D$ et al. Mortality results from a randomized prostate-cancer screening trial. N Engl J Med 2009; 360: 1310-9.

6 Ferlay J, Shin HR, Bray F, Forman D, Mathers C et al. Estimates of worldwide burden of cancer in 2008:
GLOBOCAN 2008. Int J Cancer 2010; 127: 2893917.

7 Parkin DM, Bray F, Ferlay J, Pisani P. Global cancer statistics, 2002. CA Cancer J Clin 2005; 55: 74108.

8 Kamangar F, Dores GM, Anderson WF. Patterns of cancer incidence, mortality, and prevalence across five continents: defining priorities to reduce cancer disparities in different geographic regions of the world. J Clin Oncol 2006; 24: 2137-50.

9 Zhang HF, Wang HL, Xu N, Li SW, Ji GY et al. Mass screening of 12,027 elderly men for prostate carcinoma by measuring serum prostate specific antigen. Chin Med J (Engl) 2004; 117: 67-70.

10 Gao HW, Li YL, Wu S, Wang YS, Zhang HF et al. Mass screening of prostate cancer in a Chinese population: the relationship between pathological features of prostate cancer and serum prostate specific antigen. Asian J Androl 2005; 7: 159-63.

11 McCracken M, Olsen M, Chen MS Jr, Jemal A, Thun M et al. Cancer incidence, mortality, and associated risk factors among Asian Americans of Chinese, Filipino, Vietnamese, Korean, and Japanese ethnicities. $C A$ Cancer J Clin 2007; 57: 190-205.

12 Smith RA, Cokkinides V, Brooks D, Saslow D, Brawley OW. Cancer screening in the United States, 2010: a review of current American Cancer Society guidelines and issues in cancer screening. CA Cancer J Clin 2010; 60: 99-119.

13 Draisma G, Etzioni R, Tsodikov A, Mariotto A, Wever E et al. Lead time and overdiagnosis in prostate-specific antigen screening: importance of methods and context. J Natl Cancer Inst 2009; 101: 374-83.

14 Schroder FH, Hugosson J, Roobol MJ, Tammela TL, Ciatto $S$ et al. Prostate-cancer mortality at 11 years of follow-up. N Eng J Med 2012; 366: 981-990.

15 Sartor O. Randomized studies of PSA screening: an opinion. Asian J Androl 2011; 13: 364-365.

16 Li Y, Mao JH, Zhang L, Ji GY, Pan YZ et al. Study on relationship between the expression of PSA mRNA and protein in the mononuclear cells of the peripheral blood and prostate cancer micrometastasis. Chin J Androl 2006; 20: 5-7.

17 Collin SM, Martin RM, Metcalfe C, Gunnell D, Albertsen PC et al. Prostate-cancer mortality in the USA and UK in 1975-2004: an ecological study. Lancet Oncol 2008; 9: 445-52.

18 Gomella LG, Johannes J, Trabulsi EJ. Current prostate cancer treatments: effect on quality of life. Urology 2009; 73: S28-35.

19 Jin JK, Dayyani F, Galli GE. Steps in prostate cancer progression that lead to bone metastasis. Int J Cancer 2011; 128: 2545-2561.

20 American Cancer Society Guideline for the Early Detection of Prostate Cancer Update 2010. CA Cancer J Clin 2010; 60: 70-98.

21 Raaijmakers R, Kirkels WJ, Roobol MJ, Wildhagen $\mathrm{MF}$, Schrder FH. Complication rates and risk factors of 5802 transrectal ultrasound-guided sextant biopsies of the prostate within a population-based screening program. Urology 2002; 60: 826-30.

22 Loeb S, van den Heuvel S, Zhu X, Bangma CH, Schroder $\mathrm{FH}$ et al. Infectious complications and hospital admissions after prostate biopsy in a European randomized trial. Eur Urol 2012; 61: 1110-4.

23 Chatti C, Corsia G, Yates DR, Vaessen C, Bitker MO et al. Prevention of complications of general anesthesia linked with laparoscopic access and with robotassisted radical prostatectomy. Prog Urol 2011; 21: 829-34.

24 Bivalacqua TJ, Pierorazio PM, Su LM. Open, laparoscopic and robotic radical prostatectomy: optimizing the surgical approach. Surg Oncol 2009; 18: 233-41.

25 Hugosson J, Stranne J, Carlsson SV. Radical retropubic prostatectomy: a review of outcomes and side-effects. Acta Oncol 2011; 50 Suppl 1: 92-7.

26 http://report.nih.gov/NIHfactsheets/ViewFactSheet.aspx? csid $=60$

27 Phillips MJ, Crawford ED. Prostate-specific antigen (PSA) screening: has the pendulum swung too far? Asian J Androl 2011; 13: 655-656. 